\title{
Peptide Receptor Imaging of Prostate Cancer with \\ Radiolabelled Bombesin Analogues
}

R.P.J. Schroeder ${ }^{1,2}$, W.M. van Weerden ${ }^{2}$, C. Bangma ${ }^{2}$, E.P. Krenning ${ }^{1}$ and M. de Jong ${ }^{1}$

${ }^{1}$ Department of Nuclear Medicine, Erasmus MC, Rotterdam, The Netherlands.

${ }^{2}$ Experimental Urology, Erasmus MC, Rotterdam, The Netherlands.

Correspondence address:

Rogier P.J. Schroeder, MD, MSc

Room Be331, Department of Experimental Urology

ErasmusMC (Josephine Nefkens Institute)

Dr. Molenwaterplein 50

3015 GE Rotterdam

The Netherlands

Phone: +31107043381

Fax: +31107044661

E-mail: m.hendriks-dejong@erasmusmc.nl 


\begin{abstract}
Prostate Cancer (PC) is a type of cancer that is often diagnosed at very early stages due to improved detection among man in the Western World. Current imaging techniques are not optimal to determine extent of minimal early stage PC even though this is of great clinical importance. Human PC and high-grade PIN have shown high Gastrin-Releasing Peptide Receptor (GRPR) expression, while normal prostate tissue and BPH revealed to be predominantly GRPR-negative. Radiolabelled GastrinReleasing Peptide (GRP) or bombesin (BN) analogues targeting the GRPR can be used as non-invasive tools to diagnose, monitor and potentially treat PC. These BN analogues have already proven to be able to image PC in both tumour-bearing mice and clinical patients showing no important side effects.

It's desirable that new peptides require fast-track standardised comparative testing in relevant PC models to select the best performing $\mathrm{BN}$ analogues for further evaluation in patients. Although knowledge about GRPR expression and development of new $\mathrm{BN}$ analogues can be extended, it is time to study performance of BN analogues for peptide-receptor based imaging in patients validating results of PC imaging using histopathology as a golden standard.
\end{abstract}

Keywords: bombesin, Gastrin-Releasing Peptide, peptide receptor imaging, prostatic neoplasms. 


\section{Introduction}

The medical specialism of nuclear medicine focuses on the application of radiolabelled tracers for scintigraphic imaging or radionuclide therapy of disease. Molecular nuclear medicine holds the unique potential of being able to find, diagnose and treat disease as well as to monitor treatment response.

The current evolution of knowledge in molecular biology has resulted in new targets to detect human cancer specifically. New developments in (radio)chemistry have improved molecular delivery of radionuclides to disease-target sites. Consequently this has resulted in the generation of novel tracers. Technical developments in scintigraphic instruments and reconstruction software have improved imaging modalities allowing small-animal scintigraphic techniques useful for experimental nuclear research of, especially rodent, disease models. See for review (1).

In oncology radioactive iodine introduced in the early 1950s and the widely used ${ }^{18}$ F-fluoro-2-deoxy-D-glucose $\left({ }^{18} \mathrm{~F}\right.$-FDG) have been developed as indicators of cancer cells. A promising opportunity for nuclear applications in oncology lies in the development of radiolabelled peptides that target receptors for imaging and therapy. This technique is based on targeting specific receptors that are overexpressed in tumor compared to normal tissue with highly selective radiolabelled peptides for specific imaging and monitoring. Linked to appropriate therapeutic radionuclides these peptides can also be used as radiotherapeutics in peptide receptor radionuclide therapy (PRRT).

In order to bring peptide-receptor based modalities into the clinic, radiopharmaceuticals with high affinity and high specificity for preferably cancerspecific receptors are required allowing visualisation and quantification of 
radioactivity in the tumour in a reproducible and repeatable manner. See for review (2). Somatostatin is a well-known peptide, of which analogues have been implemented successfully in the clinics to visualise and treat various neuroendocrine tumours $(3,4)$.

This review focuses on the use of the Gastrin-Releasing Peptide Receptor (GRPR) as a target for imaging and radionuclide therapy of prostate cancer (PC) using radiolabelled bombesin $(\mathrm{BN})$ analogues. The potential of these peptides for their use in early diagnosis, monitoring and therapy of PC will be discussed.

\section{Prostate cancer}

$\mathrm{PC}$ is the most frequently diagnosed cancer among men in the Western world and is the third most common cause of death (5). Specific antigen (PSA) PSA has been increasingly used to detect PC (6), although it has limited diagnostic specificity and prognostic value (7). The impact of PSA-based screening on survival has recently been reported by the European Randomised Study of screening for PC (ERSPC) study showing a significant reduction in death from prostate cancer, but at the cost of overtreatment (8). Due to PSA-based screening, the number of patients that are detected with early disease is rising. Although, final diagnosis of PC is made by histopathological confirmation of transrectal ultrasound-guided prostate biopsies, staging of the disease is essential for the decision for the most accurate treatment. It discriminates between organ-confined disease, in which local therapy such as surgery or radiation may still be beneficial, and PC beyond the confines of the gland for which a systemic approach like hormonal therapy is the first choice of treatment. None of the currently used imaging modalities are sufficiently reliable to determine the extent

of disease in early detected PC (9). Non-invasive sensitive imaging strategies to 
accurately diagnose, stage and monitor PC are therefore essential. Radiolabelled peptide-based imaging by scintigraphy may be the alternative application to fill this gap and improve diagnostic sensitivity for early PC. Also, PRRT may be an alternative tumour-specific targeting strategy in progressive patients with metastatic, therapy-resistant PC.

PET metabolic radiotracers such as ${ }^{18} \mathrm{~F}$-FDG, ${ }^{11} \mathrm{C}$-choline and ${ }^{11} \mathrm{C}$-acetate have been intensively studied for imaging PC. ${ }^{18}$ F-FDG was found to have a low accuracy in primary staging of PC mainly due to low metabolic glucose activity and urinary excretion of the metabolic tracer [10]. Choline and acetate PET was reported useful for staging of LN disease [10, 11].

ProstaScint ( ${ }^{111}$ In-capromab pendetide), a monoclonal antibody against prostate-specific membrane antigen (PSMA) as a target, is the only nuclear imaging application for PC-specific imaging. It has been approved by the American Food and Drug Administration and is put to practice for diagnostic imaging and staging of LN metastasis of PC (12).

An alternative target for PC imaging may be the GRPR using radiolabelled BN analogues.

\section{BN for peptide-targeted imaging of PC}

Gastrin-Releasing Peptide (GRP) is a 27-amino acid neuropeptide that is the mammalian homologue of the linear tetradecapeptide $\mathrm{BN}$ originally isolated from the skin of the frog; Bombina bombina. GRP binds selectively to the GRPR. It shares homology with $\mathrm{BN}$ at the amidated $\mathrm{C}$ terminal sequence in the final 7 amino acids (Figure 1). 
Using tumour autoradiography it has been reported that in human samples GRPRs are expressed at high density on the cell membranes of prostatic intraepithelial neoplasias (PIN), primary PC and invasive prostatic carcinomas, whereas normal prostate tissue and, in most cases, benign prostate hyperplasia (BPH) were predominantly GRPR-negative (13). The underlying molecular mechanisms of aberrant GRPR expression and/or activation in human PC are unknown at present. GRP interacts with GRPR inducing cell growth in various tumours including PC (14). The relation between GRPR and PC stage is still uncertain. PC in xenografts derived from late stage androgen-independent disease showed lower expression of the GRPR than xenografts established from early androgen-dependent PC (15). Besides in PC GRPR is also over expressed in several other human tumour types and metastases including breast-, colon-, lung-, ovary-, renal, CNS and head or neck squamous cancer $(14,16)$.

Four subtypes of the cell surface BN receptor are known. Among them three are mammalian: the $\mathrm{NMB}$ receptor $\left(\mathrm{BB}_{1}\right)$, Gastrin-Releasing Peptide Receptor $\left(\mathrm{GRPR} / \mathrm{BB}_{2}\right)$ and $\mathrm{BN}$ receptor subtype $3\left(\mathrm{BRS}-3 / \mathrm{BB}_{3}\right)$. A fourth receptor, $\mathrm{BB}_{4}$, is only found in amphibians $(14,17)$. The only well characterised receptor to which GRP and BN bind with high affinity is the GRPR (BB2).

\section{Research on GRPR and BN-analogues}

The finding of GRPR overexpression in PC and other cancer types stimulated the search for BN/GRP peptide analogues that could bind with high potency to the GRPR. GRP-antagonistic analogues have been developed to realise antiproliferative effects and indeed this has led to promising growth-inhibitory effects in human GRPRpositive PC cell lines and human PC3-bearing mice (18). Besides this approach it was 
also proposed that GRP analogues could be used as molecular tracers for imaging and treatment of PC tumours, when those analogues would be linked to a radioactive agent $(13,19)$. This application has been studied in both preclinical and clinical settings.

Synthetic BN analogues can be categorized into two different types based on their structures. Type A-analogues are truncated with only a portion, usually BN [714] at the $\mathrm{C}$ terminus, of the peptide retained. This $\mathrm{C}$ terminal sequence is generally thought to be essential for receptor recognition, signal transduction, and biologic function (Figure 1). Type B analogues on the other hand are synthesized in full length. In these analogues usually one or more amino acid residues are selectively replaced.

A type A-analogue is generally thought to be favourable while it is more stable than the full-length type B tetradecapeptides for in vivo applications and still binds to the GRPR adequately $(20,21)$. For radiolabelling of GRP-analogues biomolecules are generally designed in a way to keep the labelling site at distance from the receptor-binding site, but at the same time tag the radiometal into the molecule in an irreversible way leading to stable radiolabelled derivatives.

\section{$\underline{\text { Preclinical }}$}

The development of new analogues is mostly aimed at improving the sensitivity and specificity of GRPR targeting. Several new BN-analogues have been developed and tested for their potential in early diagnosis, monitoring and therapy in vivo. In a preclinical setting general peptide characteristics such as stability, biodistribution and toxicity were often tested using the human PC3 cell line and the experimental PC3 bearing xenograft model. 
A potent ${ }^{99 \mathrm{~m}}$ Tc-based BN analogue designed for GRPR based targeting and tested in the PC3 xenograft model with the highest absolute tumor-uptake in animals described in literature, is Demobesin-1 (22). Other promising BN-analogues that were tested in preclinical studies using PC3 bearing mice include the DOTA chelated compounds AMBA and Pesin, the DTPA chelated compound MP2653 (Compound 3 in Visser et al.) and [DTPA1, Lys3(Pm-DADT), Tyr4]BN (for amino acid sequence of native $\mathrm{BN}$ and $\mathrm{BN}$-analogues see Table 1) (23-26).

Rogers et al. introduced the radiolabelled $\mathrm{BN}$ analogue ${ }^{64} \mathrm{Cu}-\mathrm{DOTA}$-Aoc$\mathrm{BN}$ [7-14] as the first GRPR targeting radiopharmaceutical to use for PC-imaging with PET (27). The BN-analogue ${ }^{18} \mathrm{~F}-\mathrm{FB}-\left[\mathrm{Lys}^{3}\right] \mathrm{BN}$ designed for GRPR-targeted PET has also been tested showing promising results for PC imaging (28).

At the moment a valid comparison of available analogues for PC detection is difficult as standardisation between the preclinical studies performed is lacking. Therefore we recently performed a standardised preclinical study comparing four DOTA-chelated $\mathrm{BN}$ agonists and one N4-chelated $\mathrm{BN}$ antagonist (manuscript submitted).

GRPR will internalise into the cell when it is activated by an agonistic ligand binding the receptor. Internalisation of the receptor-radioligand complex has always been thought to be a crucial step for optimal imaging and therapy. It would provide essential accumulation and retention of radioactivity in the cell, thus increasing the radioactive signal at the target site. Interestingly, high-affinity somatostatin receptor antagonists that poorly internalise into tumour cells have recently shown an equal or even higher tumour uptake and a higher retention rate in preclinical studies as opposed to agonists, which do internalise (29). Cescato et al showed that GRPR antagonists may be superior targeting agents compared to GRPR agonists as well 
(30). These data suggest a change of paradigm in which the intensified use of antagonistic in preference to agonistic analogues would be justified.

PC3 and Du145 cell lines are commonly used in GRPR binding studies. Both cell lines are androgen-independent and show no expression of the androgen receptor or PSA; characteristics which are essential to PC patients (31). On the other hand, both cell lines express high levels of GRPR (32). Therefore they remain functional for use in GRPR based studies. In a panel of 12 established human PC xenograft models representing the different stages of human PC, Visser et al. showed that high GRP receptor density was only observed in androgen-dependent PC xenografts. If this result can be translated to the clinical situation, it might indicate that high GRPR expression is predominantly present in the early, androgen-dependent, stages of PC and not in later stages. In addition, in this preclinical study, androgen ablation strongly reduced GRPR expression in androgen-dependent tumours indicating that GRPR expression in human PC is androgen-regulated (15). Thus GRPR based imaging may be especially relevant in early PC and less suited for hormone-treated patients with late stage disease.

\section{Clinical}

Few BN-analogues have been studied in PC patients. Van der Wiele published clinical data on ${ }^{99 \mathrm{~m}} \mathrm{Tc}-\mathrm{RP} 527$ in four androgen independent PC patients with metastatic bone lesions. Selective uptake was observed in one patient and $50 \%$ of the bone lesions could be visualised by SPECT in this patient. No short-term adverse or subjective effects were described in any of the subjects (33).

The GRP analogue [Leu13]BN which complexes with ${ }^{99 \mathrm{~m}} \mathrm{Tc}$ was described in an article by Varvarigou et al (34). Herein [Leu13]BN showed to be a promising BN- 
analogue in GRPR expressing malignancies other than PC. A first clinical study using ${ }^{99 \mathrm{~m}} \mathrm{Tc}$-[Leu13]BN for imaging in an androgen-dependent PC patient by De Vincentis et al. resulted in the visualisation of the primary PC in this patient without observing relevant side-effects (35). Scopinaro et al. proceeded evaluating the same analogue in $8 \mathrm{PC}$ patients and reported all 8 primary PCs to be visualized in the prostate fossa by SPECT while 2 patients with benign adenomas did not show uptake. In this study SPECT showed uptake in obturator nodes which was proven to be cancer-specific after histopathology in 3 patients. MRI or CT did not show these LN metastases (36). After this study Vincentis et al. reported SPECT-detected PC in 12/12 patients with androgen-dependent PC and loco-regional LN visualisation in 4 patients. Eleven patients got operated and results were histologically confirmed by surgical specimens. No short-term adverse effects were stated (37). In a phase I study in hormone refractory PC patients aiming at PC therapy, using the ${ }^{177}$ Lu-labelled BN analogue AMBA, SPECT imaging revealed lesions in 5 out of 7 patients with adittional high pancreatic uptake of radioactivity (38). For an overview of clinical PC-imaging studies see table 2.

Recently, Froberg et al reported high uptake of the BN-agonist MP2248 and antagonist Demobesin-1 in the pancreatic region of 4 PC patients. Retention in the pancreas after injection of ${ }^{111} \mathrm{In}-\mathrm{MP} 2248$ was much longer than retention of ${ }^{99 \mathrm{~m}} \mathrm{Tc}-$ Demobesin-1 (39).

Only very few PET studies have been reported to date for visualisation and quantification of GRPR expression in PC patients. A clinical study using ${ }^{68} \mathrm{Ga}-$ DOTABOM has been described by Hofmann et al. (40).

\section{Future prospectives}


Although expression of the GRPR in various tissue types and tumours has been studied it requires further investigation. In case of PC, knowledge about the androgen regulation of GRPR is of great clinical relevance, as it will strongly determine the potential use of BN-based imaging and therapy in the different stages of PC.

A valid comparison of $\mathrm{BN}$-analogues for $\mathrm{PC}$ detection, based on literature, is difficult as standardisation between studies is lacking. Differences in potency between existing and future $\mathrm{BN}$-analogues need to become clear. Standardised studies with appropriate design to compare analogues are therefore required.

The field of radiolabelled peptides for receptor-based targeting of $\mathrm{PC}$ is evolving. New $\mathrm{BN}$-analogues are being designed in order to improve characteristics like specificity, sensitivity and stability in vivo. BN-peptides should have high affinity for to the GRPR, remain intact in vivo for a long time and their clearance from circulation should be fast. Furthermore, for peptide-receptor targeting, receptors of interest should ideally be highly expressed in the disease tissue only. High expression in (non-cancerous) non-targeted tissue will cause non-specific peptide binding resulting in a high background signal while scanning and toxicity to healthy tissue when therapy is concerned. When developing a $\mathrm{BN}$-analogue, besides taking its amino acid sequence into consideration, attention should be paid to the selection of an appropriate chelator while this determines which radionuclides can be complexed with the analogue.

Recent findings suggest that antagonistic GRPR-based peptides show higher tumour uptakes and radioactivity retention in PC tissue compared to agonistic peptides with comparable binding affinities. This finding paves the way for intensified development of new $\mathrm{BN}$-antagonists. Also from a pharmacological point of view this change in paradigm is favourable, as antagonists may not induce the endocrinological 
side effects known from agonists, such as stimulation of tumour growth. Especially when a therapeutic dose is taken into account, agonistic BN-peptides could cause (side-)effects for PC patients. More research needs to be done to reveal the underlying mechanism in binding difference between agonistic and antagonistic peptides. To improve peptide-receptor targeting and increase the dose in target cells it might be suggested to test a cocktail of $\mathrm{BN}$-agonists and antagonists for simultaneous administration.

\section{Acknowledgements}

This work was supported by The Dutch Cancer Society / KWF (Grant Number: 12977368). 


\section{References}

1. Rowland, D. J., and Cherry, S. R. (2008) Semin Nucl Med 38, 209-22.

2. Cook, G. J. (2003) Br J Radiol 76 Spec No 2, S152-8.

3. Krenning, E. P., Bakker, W. H., Breeman, W. A., Koper, J. W., Kooij, P. P., Ausema, L., Lameris, J. S., Reubi, J. C., and Lamberts, S. W. (1989) Lancet 1, 242-4.

4. Van Essen, M., Krenning, E. P., De Jong, M., Valkema, R., and Kwekkeboom, D. J. (2007) Acta Oncol 46, 723-34.

5. Jemal, A., Siegel, R., Ward, E., Hao, Y., Xu, J., Murray, T., and Thun, M. J. (2008) CA Cancer J Clin 58, 71-96.

6. Stamey, T. A., Yang, N., Hay, A. R., McNeal, J. E., Freiha, F. S., and Redwine, E. (1987) N Engl J Med 317, 909-16.

7. Thompson, I. M., Pauler, D. K., Goodman, P. J., Tangen, C. M., Lucia, M. S., Parnes, H. L., Minasian, L. M., Ford, L. G., Lippman, S. M., Crawford, E. D., Crowley, J. J., and Coltman, C. A., Jr. (2004) N Engl J Med 350, 2239-46.

8. Schroder, F. H., Hugosson, J., Roobol, M. J., Tammela, T. L., Ciatto, S., Nelen, V., Kwiatkowski, M., Lujan, M., Lilja, H., Zappa, M., Denis, L. J., Recker, F., Berenguer, A., Maattanen, L., Bangma, C. H., Aus, G., Villers, A., Rebillard, X., van der Kwast, T., Blijenberg, B. G., Moss, S. M., de Koning, H. J., and Auvinen, A. (2009) N Engl J Med 360, 1320-8.

9. el-Gabry, E. A., Halpern, E. J., Strup, S. E., and Gomella, L. G. (2001) Oncology (Williston Park) 15, 325-36; discussion 39-42.

10. Jana, S., and Blaufox, M. D. (2006) Semin Nucl Med 36, 51-72.

11. de Jong, I. J., Pruim, J., Elsinga, P. H., Vaalburg, W., and Mensink, H. J. (2003) J Nucl Med 44, 331-5.

12. Sartor, O., and McLeod, D. (2001) Urology 57, 399-401.

13. Markwalder, R., and Reubi, J. C. (1999) Cancer Res 59, 1152-9.

14. Jensen, R. T., Battey, J. F., Spindel, E. R., and Benya, R. V. (2007) Pharmacol Rev.

15. de Visser, M., van Weerden, W. M., de Ridder, C. M., Reneman, S., Melis, M., Krenning, E. P., and de Jong, M. (2007) J Nucl Med 48, 88-93.

16. Cornelio, D. B., Roesler, R., and Schwartsmann, G. (2007) Ann Oncol 18, 1457-66.

17. Anastasi, A. (1971) Naunyn Schmiedebergs Arch Pharmakol 269, 135-9.

18. Stangelberger, A., Schally, A. V., and Djavan, B. (2008) Eur Urol 53, 890900.

19. Schally, A. V., and Nagy, A. (1999) Eur J Endocrinol 141, 1-14.

20. Yang, Y. S., Zhang, X., Xiong, Z., and Chen, X. (2006) Nucl Med Biol 33, 371-80.

21. Moody, T. W., Crawley, J. N., and Jensen, R. T. (1982) Peptides 3, 559-63.

22. Nock, B., Nikolopoulou, A., Chiotellis, E., Loudos, G., Maintas, D., Reubi, J. C., and Maina, T. (2003) Eur J Nucl Med Mol Imaging 30, 247-58.

23. Lantry, L. E., Cappelletti, E., Maddalena, M. E., Fox, J. S., Feng, W., Chen, J., Thomas, R., Eaton, S. M., Bogdan, N. J., Arunachalam, T., Reubi, J. C., Raju, N., Metcalfe, E. C., Lattuada, L., Linder, K. E., Swenson, R. E., Tweedle, M. F., and Nunn, A. D. (2006) J Nucl Med 47, 1144-52.

24. Zhang, H., Schuhmacher, J., Waser, B., Wild, D., Eisenhut, M., Reubi, J. C., and Maecke, H. R. (2007) Eur J Nucl Med Mol Imaging 34, 1198-208. 
25. de Visser, M., Bernard, H. F., Erion, J. L., Schmidt, M. A., Srinivasan, A., Waser, B., Reubi, J. C., Krenning, E. P., and de Jong, M. (2007) Eur J Nucl Med Mol Imaging 34, 1228-38.

26. Lin, K. S., Luu, A., Baidoo, K. E., Hashemzadeh-Gargari, H., Chen, M. K., Brenneman, K., Pili, R., Pomper, M., Carducci, M. A., and Wagner, H. N., Jr. (2005) Bioconjug Chem 16, 43-50.

27. Rogers, B. E., Bigott, H. M., McCarthy, D. W., Della Manna, D., Kim, J., Sharp, T. L., and Welch, M. J. (2003) Bioconjug Chem 14, 756-63.

28. Zhang, X., Cai, W., Cao, F., Schreibmann, E., Wu, Y., Wu, J. C., Xing, L., and Chen, X. (2006) J Nucl Med 47, 492-501.

29. Ginj, M., Zhang, H., Waser, B., Cescato, R., Wild, D., Wang, X., Erchegyi, J., Rivier, J., Macke, H. R., and Reubi, J. C. (2006) Proc Natl Acad Sci U S A 103, 16436-41.

30. Cescato, R., Maina, T., Nock, B., Nikolopoulou, A., Charalambidis, D., Piccand, V., and Reubi, J. C. (2008) J Nucl Med 49, 318-26.

31. Marques, R. B., van Weerden, W. M., Erkens-Schulze, S., de Ridder, C. M., Bangma, C. H., Trapman, J., and Jenster, G. (2006) Eur Urol 49, 245-57.

32. Reile, H., Armatis, P. E., and Schally, A. V. (1994) Prostate 25, 29-38.

33. Van de Wiele, C., Dumont, F., Vanden Broecke, R., Oosterlinck, W., Cocquyt, V., Serreyn, R., Peers, S., Thornback, J., Slegers, G., and Dierckx, R. A. (2000) Eur J Nucl Med 27, 1694-9.

34. Varvarigou, A. D., Scopinaro, F., Leondiadis, L., Corleto, V., Schillaci, O., De Vincentis, G., Sourlingas, T. G., Sekeri-Pataryas, K. E., Evangelatos, G. P., Leonti, A., Xanthopoulos, S., Delle Fave, G., and Archimandritis, S. C. (2002) Cancer Biother Radiopharm 17, 317-26.

35. De Vincentis, G., Scopinaro, F., Varvarigou, A., Ussof, W., Schillaci, O., Archimandritis, S., Corleto, V., Longo, F., and Delle Fave, G. (2002) Tumori 88, S28-30.

36. Scopinaro, F., De Vincentis, G., Varvarigou, A. D., Laurenti, C., Iori, F., Remediani, S., Chiarini, S., and Stella, S. (2003) Eur J Nucl Med Mol Imaging 30, 1378-82.

37. De Vincentis, G., Remediani, S., Varvarigou, A. D., Di Santo, G., Iori, F., Laurenti, C., and Scopinaro, F. (2004) Cancer Biother Radiopharm 19, 81-4.

38. Bodei, L., Ferrari, M., Nunn, A., Llull, J., Cremonesi, M., Martano, L., Laurora, G., Scardino, E., Tiberini, S., Bufi, G., Eaton, S., de Cobelli, O., and Paganelli, G. (2007) Eur J Nucl Med Mol Imaging 463P.

39. Froberg, A. C., Visser, M., Maina, T., Erion, J., de Swart, J., de Jong, M., and Krenning, E. P. (2006) Journal of Nuclear Medicine 47; 429P.

40. Hofmann, M., Machtens, S., Stief, C., Maecke, H., Boerner, A. R., and Knapp, W. H. (2004) Eur J Nucl Med Mol Imaging 45: 449P. 


\section{Legends}

Table 1

Amino acid sequence of native BN (14 amino acids) and the BN-analogues described. $\mathrm{BN}=$ bombesin, $\operatorname{Ref}(\mathrm{s})=$ reference $(\mathrm{s})$.

Chelators: N4 $=6-\{\mathrm{p}-[($ carboxymethoxy)acetyl $]$ aminobenzyl $\}-1,4,8,11$ tetraazaundecane, DOTA $=$ 1,4,7,10-tetraazacyclododecane-1,4,7,10-tetraacetic acid, $\mathrm{DTPA}=$ Diethylene triamine pentaacetic acid, Pm-DADT $=$ diaminedithiol, $\mathrm{FB}=4-$ Fluorobenzoyl, $\mathrm{N}_{3} \mathrm{~S}=$ dmgly-L-ser-L-cys(acm).

Linkers: BzDig $=$ p-aminobenzyldiglycolic acid, $\mathrm{PEG}=$ polyethylene glycol, $\mathrm{Aoc}=8$ carbon linker, Gly-5aVa = 5-amino-valeroyl, Aca = 6-amino-n-hexanoic acid. Introduced amino acids: Phe $=$ Phenylalanine, ACMPip $=4$-Aminocarboxymethylpiperidine (non-natural amino acid), Tha $=\beta$-(2-Thienyl)-alanine (nonnatural amino acid), $\beta$-Ala $=\beta$-Alanine (non-natural amino acid), Nle $=$ Norleucine, Lys $=$ Lysine, Cys $=$ Cysteine, Pro $=$ Proline, Tyr $=$ Tyrosine.

Table 2

Overview of clinical studies using BN-analogues for PC-tumour imaging patients Ref $=$ reference, $\mathrm{BN}=$ bombesin, $\mathrm{PC}=$ prostate cancer, $\mathrm{AI}=$ androgen independent, $\mathrm{AD}=$ androgen dependent ${ }^{+}=$visualized by scintigraphy, ${ }^{-}=$not visualized by scintigraphy, $\operatorname{pt}(\mathrm{s})=$ patient(s), h.c. $=$ histologically confirmed, $\mathrm{BC}=$ breast carcinoma, $\mathrm{BAp}=$ benign adenoma of the prostate, $\mathrm{LN}=$ lymph node, $\mathrm{EPS}=$ extraprostatic spread.

Figure 1

Amino acid sequence of the 27-amino acid neuropeptide GRP and its mammalian homologue; the linear tetradecapeptide $\mathrm{BN}$. 
Table 1

\begin{tabular}{|c|c|c|c|c|c|c|c|c|c|c|c|c|c|c|c|c|c|c|}
\hline Analogue & $\operatorname{Ref}(\mathrm{s})$ & Radionuclide & Chelator & Linker & Amin & 10 aci & id seq & quenc & & & & & & & & & & \\
\hline & & & & & 1 & 2 & 3 & 4 & 5 & 6 & 7 & 8 & 9 & 10 & 11 & 12 & 13 & 14 \\
\hline Native BN & [14] & & & & pGlu & $\operatorname{Gln}$ & $\operatorname{Arg}$ & Leu & Gly & Asn & Gln & $\operatorname{Trp}$ & Ala & $\mathrm{Val}$ & Gly & His & Leu & Met-NH \\
\hline Demobesin-1 & {$[22]$} & ${ }^{99 \mathrm{~m}} \mathrm{Tc}$ & $\mathrm{N}_{4}$ & BzDig & & & & & & DPhe & $G \ln$ & $\operatorname{Trp}$ & Ala & $\mathrm{Val}$ & Gly & His & $\begin{array}{l}\text { Leu- } \\
\text { NHEt }\end{array}$ & \\
\hline AMBA & {$[23,38]$} & ${ }^{177} \mathrm{Lu}$ & DOTA & \begin{tabular}{|l|} 
G-4- \\
aminobenzyl
\end{tabular} & & & & & & & Gln & $\operatorname{Trp}$ & Ala & $\mathrm{Val}$ & Gly & His & Leu & Met-NH \\
\hline Pesin & [24] & ${ }^{68 / 67} \mathrm{Ga},{ }^{177} \mathrm{Lu}$ & DOTA & $\mathrm{dPEG}_{4}$ & & & & & & & Gln & Trp & Ala & $\mathrm{Val}$ & Gly & His & Leu & Met-NH \\
\hline MP2653 & [25] & ${ }^{111} \mathrm{In}$ & DTPA & & & & & & ACMPip & Tha & Gln & $\operatorname{Trp}$ & Ala & $\mathrm{Val}$ & $\beta$-Ala & His & Tha & Nle- $\mathrm{NH}_{2}$ \\
\hline \begin{tabular}{|l} 
[DTPA1,Lys3 \\
(Pm-DADT), \\
Tyr4]BN*
\end{tabular} & [26] & ${ }^{99 \mathrm{~m}} \mathrm{Tc}$ & Pm-DADT** & & pGlu & Gln & Lys & Tyr & Gly & Asn & Gln & $\operatorname{Trp}$ & Ala & $\mathrm{Val}$ & Gly & His & Leu & Met-NH ${ }_{2}$ \\
\hline Aoc-BN(7-14) & [27] & ${ }^{64} \mathrm{Cu}$ & DOTA & Aoc & & & & & & & Gln & Trp & Ala & $\mathrm{Val}$ & Gly & His & Leu & Met-NH \\
\hline [Lys3]BN & [28] & ${ }^{18} \mathrm{~F}$ & FB & & pGlu & Gln & Lys & Leu & Gly & Asn & Gln & $\operatorname{Trp}$ & Ala & Val & Gly & His & Leu & Met-NH \\
\hline RP527 & [33] & ${ }^{99 \mathrm{~m}} \mathrm{Tc}$ & $\mathrm{N}_{3} \mathrm{~S}$ & Gly-5aVa & & & & & & & Gln & $\operatorname{Trp}$ & $\mathrm{Ala}$ & Val & Gly & His & Leu & Met-NH \\
\hline [Leu13] BN & [34-37] & ${ }^{99 \mathrm{~m}} \mathrm{Tc}$ & & Aca*** & Cys & $\mathrm{Gln}$ & Arg & Leu & Gly & Asn & Gln & Trp & Ala & Val & Gly & His & Leu & Met-NH \\
\hline MP2248 & [39] & ${ }^{111} \mathrm{In}$ & DTPA & & Pro & $\operatorname{Gln}$ & Arg & Tyr & Gly & Asn & Gln & $\operatorname{Trp}$ & Ala & Val & Gly & His & Leu & Met-NH \\
\hline DOTABOM & [40] & ${ }^{68} \mathrm{Ga}$ & DOTA & & & & & & & & & & & & & & & \\
\hline
\end{tabular}

* In this compound DTPA is not used as a chelator for radionuclide complexation, but as a built-in pharmacokinetic modifier to reduce hepatobiliary clearance.

** Linked to Lys on position 3.

*** In between amino acids 1 and 2 . 
Table 2

\begin{tabular}{|c|c|c|c|c|c|c|c|c|}
\hline Authors & Ref & Radionuclide & BN-analogue & $\begin{array}{l}\text { Total activity } \\
(\mathrm{MBq})\end{array}$ & $\begin{array}{c}\text { Peptide } \\
\text { mass }\end{array}$ & $\begin{array}{l}\text { PC population } \\
\text { in study }\end{array}$ & $\mathbf{P C}$ & Extra \\
\hline Van der Wiele et al & {$[33]$} & $\begin{array}{c}{ }^{99 \mathrm{~m}} \mathrm{Tc} \\
(\mathrm{SPECT})\end{array}$ & RP527 & 555 & $3 \mathrm{ng} / \mathrm{kg}$ & $4 \mathrm{AI}$ & 1 & $\begin{array}{c}\text { In the one } \mathrm{PC}^{+} \text {pt } 50 \% \text { of h.c. bone } \\
\text { lesions visualized } \\
4 / 6 \mathrm{BC} \mathrm{pts}^{+}\end{array}$ \\
\hline De Vincentis et al & {$[35]$} & $\begin{array}{c}{ }^{99 \mathrm{~m}} \mathrm{Tc} \\
(\mathrm{SPECT})\end{array}$ & [Leu13]BN & 185 & $0,7 \mu \mathrm{g}$ & $1 \mathrm{AD}$ & 1 & \\
\hline Scopinaro et al & {$[36]$} & $\begin{array}{l}{ }^{99 \mathrm{~m}} \mathrm{Tc} \\
(\mathrm{SPECT})\end{array}$ & [Leu13]BN & 185 & $0,7 \mu \mathrm{g}$ & $8 \mathrm{AD}$ & 8 & $\begin{array}{c}3 \mathrm{LN}^{+} \text {all h.c.; all negative MRI/CT } \\
2 \text { benign PC pts }\end{array}$ \\
\hline De Vincentis et al & {$[37]$} & $\begin{array}{l}{ }^{{ }^{99 m} \mathrm{Tc}} \\
(\mathrm{SPECT})\end{array}$ & [Leu13]BN & 185 & $0,7 \mu \mathrm{g}$ & $12 \mathrm{AD}$ & 12 & $\begin{array}{c}2 \text { BAp pts } \\
4 \mathrm{LN}^{+} \text {all h.c.; } 3 / 4 \text { positive CT/MRI } \\
\text { PC }^{+} \text {h.c. in } 11 / 12 \text { pts }\end{array}$ \\
\hline Bodei et al & {$[38]$} & $\begin{array}{c}{ }^{177} \mathrm{Lu} \\
(\mathrm{SPECT})\end{array}$ & AMBA & $1140-1940$ & $\begin{array}{c}\text { Not } \\
\text { mentioned }\end{array}$ & $7 \mathrm{AI}$ & 5 & $\begin{array}{l}\text { Study primarily aimed for PC } \\
\text { therapy }\end{array}$ \\
\hline Hoffman et al & {$[40]$} & $\begin{array}{l}{ }^{68} \mathrm{Ga} \\
(\mathrm{PET})\end{array}$ & DOTABOM & $26-80$ & $24 \mathrm{nmol}$ & $11 \mathrm{AD}$ & 11 & $3 \mathrm{Ln}+\& 2$ pts with EPS + (all h.c.) \\
\hline
\end{tabular}


Figure 1

\section{Gastrin releasing peptide}

Ala-Pro-Val-Ser-Val-Gly-Gly-Thr-Val-Leu-Ala-Lys-Met-Try-Pro-Arg-

(Gly-Asn-His-)Trp-Ala-Val-Gly-His-Leu-Met-NH

C terminus

\section{Bombesin}

pGlu-Gln-Arg-Leu-

(Gly-Asn-GIn-)Trp-Ala-Val-Gly-His-Leu-Met-NH

C terminus 